fraction of a wave-length apart and symmetrically connected to the central receiver in such a manner that certain instrumental defects inherent in the use of open aerials can be eliminated. It is convenient to use a visual receirer of the cathode-ray tube type, and various tests have demonstrated that the inherent instrumental accuracy of such apparatus is somewhat higher than that previously attainable.

When used for taking bearings on short-wave transmitting stations, however, it was found that the accuracy was not materially better than that hitherto obtained. It is to be concluded, therefore, that on the short wave-lengths under consideration, a severe limit is set to the accuracy of radio direction finding under certain conditions by vagaries in the propagation of the electric waves employed. The direction-finding instruments indicate the actual direction of arrival of the waves to a high order of accuracy, but this is not necessarily the direction of the transmitter, but rather that of the point of reflection or scattering of the waves from the ionosphere. It is perhaps fortunate that it is possible to avoid using the bearings obtained under such conditions, and increased knowledge and experience will soon indicate in precisely what circumstances it is safe to rely upon the radio bearings obtained. Meanwhile, the use of these short-wave direction. finders is adding considerably to our knowledge of the mode of propagation of electric waves through the ionosphere.

In the range of wave-lengths below 10 metres, direction finding is in the early stages of development, but instruments of the closed loop and spaced aerial types have already been used for ascertaining the possibilities of the art on wavelengths down to 3 metres. It seems likely that within this wave-length band, some application is likely to be found in ascertaining the positions of radio sounding balloon transmitters at ranges up to one hundred miles or so. In this sphere, however, much more research is needed on the propagation of waves as well as on the design and construction of the direction-finding instruments.

R. L. S.R.

\title{
BIOLOGY, THE SCHOOL AND SOCIETY*
}

\author{
By T. H. HAWKINS \\ Education Officer, British Social Hygiene Council
}

$\mathrm{T}^{\mathrm{H}}$ HE acceleration of scientific invention during the last generation has been such that it has now considerably outdistanced the ability of man to assimilate knowledge and to make it an essential part of his social and ethical relationships. This was the theme of the address given before the Ninth Imperial Social Hygiene Congress by Prof. J. Ritchie, of the University of Edinburgh, who suggested that the failure is in some measure due to the exclusiveness of science, and that its remedy partly lies in the creation of a world-wide appreciation of the social and moral implications of scientific knowledge. That this appreciation can in part be brought about by biological knowledge was the keynote of the educational sessions of the Congress, which was attended by delegates from all parts of the Empire.

At the opening session, the speakers concerned themselves with the teaching of biology as a factor in health and character training. Mr. C. R. E. Gillett, University. of Reading, in comparing the older public and newer State schools, suggested that the latter are now attempting to turn out a product which hitherto has presumably belonged

- Survey of the educational sessions of the Ninth Imperial Social Hygiene Congress, held in the Hastings Hall, British Jedical Association House, July 10-14. exclusively to the former, namely, a citizen qualified to play his part in our changing form of democratic government. This citizen would be keenly aware of his responsibilities to the community and would be imbued with such a sense of social duty that he would readily undertake those tasks which contribute to the welfare and establishment of communal life. But whether the will to serve has demonstrably expressed itself is a matter of great doubt, and here only education would make it effective. The part that biology can play in health and character formation will only become apparent if the pupil be made to feel keenly aware of the value of his training. Active co-operation will be needed between teachers of physical training, domestic science, and biology, and this should be unified by a 'positive' attitude towards health on the part of the school staff as a whole. The part of the biological teacher in this co-ordinated form of health education would be that of the true scientific investigator, seeking with the children to elucidate real problems, rather than being a mere imparter of factual information. If children were allowed to cooperate fully in the elucidation of simple medicobiological problems, they would not fail to develop 
a critical and inquiring attitude to their own health problems, one which is active and forward and not a mere morbid dwelling on bodily ills.

In considering character formation, it is well to define the main objectives of biological teaching; first, the acquisition of information ; secondly, the development of methods of thinking ; thirdly, the induction and application of principles; and fourthly, the formation of attitudes. The forma. tion of desirable attitudes can be fostered by effective science teaching based on direct personal experiences. The problem of sex education is complex and difficult, but at least the biology of sex can be treated objectively by the teacher as a problem which is as vital as any other. Whether the teacher is able to deal with the ethical, moral and emotional aspects of sex will depend largely on his own personality and character. The recognition that most of the problems besetting the world are fundamentally biological might lead people to seek for biological solutions. Ecology and heredity could be used to discuss the inter-relationships of life and the effects of selective breeding, while, in common with other sciences, laboratory methods could be used to distinguish between speculation and opinion.

Dr. F. C. Kelly, director of the Iodine Educational Bureau, dealt with the efforts that are being made to reduce the gap between those who are engaged in ascertaining the theoretical facts of nutrition and those whose duty is the application of that knowledge to the practical affairs of public health. Co-operation between educationists, medical men and agriculturists might be considerably extended. While the vital problem of malnutrition and sub-standard health is fundamentally one of food production, yet education also has an essential place. The application of education should be extended in two directions. The newer knowledge of nutrition and its principles must first be made known to those who are in a position to influence others, such as Government officials, health, agriculture and education officers, employers of labour, missionaries and other welfare workers. But there is also the great problem of educating those whose nutrition it is desired to improve. Besides teaching the right use of food in relation to such aspects as cooking, storage and preservation, there is urgent need for educational measures to overcome innate conservation, prejudice, religious scruples and food taboos. The teaching of biology in schools might help to overcome these prejudices by reaching towards the essential unity of Nature, and, in checking the continually increasing pace of analytical inquiry, effect a harmonious synthesis of all the complex knowledge now at our disposal.

Prof. H. D. Kay, University of Reading, suggested that the gaps in the teaching of nutritional science will only be filled when two conditions have been satisfied. One is the need for the training of a sufficient number of teachers capable of dealing with agricultural and rural biology to enable all senior and secondary school children in country districts and small towns to receive adequate elementary instruction in environmental science. The other is the need for the training of a sufficient number of teachers having a sound up-to-date knowledge of the elements of nutritional science to enable all pupils in senior and secondary schools, in town and country alike, to receive adequate instruction in this field. That the former condition merits immediate attention is borne out by the fact that less than ten per cent of the future farmers of Great Britain attend agricultural colleges or farm institutes, whereas practically all now pass through senior or secondary schools.

An educationist, Mr. W. L. Sumner, of University College, Nottingham, went on to explain the function of the school in creating an ideal of health as an attainable goal. Whilst no detailed physiological knowledge is required, on the other hand a smattering of the old formal botany and zoology would not suffice, a statement which was expanded by Prof. L. P. W. Renouf, University of Cork, and Mr. J. H. Lloyd, University of Wales. Throughout all science courses, the human and everyday value of science should be stressed. Food and feeding and problems connected therewith might find their way into other school studies. Arithmetic might deal with food prices and food values, lists of ingredients, comparison of consumption, etc. The pages of history and geography are full of stories of diet which could be used to good advantage. A knowledge of elementary dietetic principles would enable the public to distinguish between what is true and what is misleading in the advertising of foodstufis. This knowledge would have far-reaching effects on the health of the nation; during the last twenty years amazing changes have taken place, but the problem of better food for all has still to be resolutely tackled. The psychological and xsthetic aspects of food and feeding are further considerations to which the teacher might give his attention. The presentation of food in attractive form and in pleasant surroundings is a matter in which English people might gain much from Continental methods. Although it would be inadvisable to attempt to copy directly these methods, their study might lead to the introduction of an eclectic spirit.

With these considerations in mind, the Congress turned to discuss the equipment of the ordinary teacher in biology. Although the development of biology in schools during the last ten years has been really remarkable, Prof. Ritchie pointed out that Great Britain still lags far behind nearly every 
other country in the world, and school courses are often ill-adapted for their purpose in education. Now that the educationist has realized that the pupil is no empty sarcophagus into which the mummy called 'information' should be stuffed, then the objective of making use of the child's own initiative and response might be achieved. As in the world of living things, the educationist is realizing that it is the response from within and not the impression from without which counts. Another conception which is helping to direct the flow of educational practice has arisen from the difficulties and disturbances which have upset the peaceful course of national life in recent years. $\mathrm{By}$ inducing independence of thought and balance of mind, school education should lay the founda. tions of mental stability and of the appreciation of the significance of social relationships which would prepare the child for the responsibilities of citizenship.

The fundamental interest of ehildren in Nature opens up easy ways of inducing response and initiative. To be effective, biology teaching should run in graded stages throughout the whole school period, as indeed it does in many countries. Further, it should place the pupil in contact with living things, in school and out of school, as a basis for the understanding of the activities and relationships of life. Finally, it should in its later stages boldly proceed to link man with the rest of the animate world, and show how he, too, in his relation to natural environment, and to his animate or social environment, is constrained by the laws of Nature.

The difficulty of finding teachers qualified to conduct biology teaching with these ends in view, leads to the question as to whether the universities have attempted to meet the need for teachers of biology. They should introduce more of the living animal ; there should be more first-hand contact with Nature, a greater familiarity with British plants and animals, their relationships with each other and with man himself. In their glorification of research, which is often pedestrian in nature, and their belittling of school teaching, further blame must be apportioned to the universities.

Other speakers amplified three main points which arose from the addresses: the need for inculcating the right mental outlook and for developing perspective and initiative, and a condemnation of academic biology. During the discussions, one felt that a genuine attempt is being made to meet those criticisms of school science teaching which is contained in the Spens Report, and that a step forward has been made to apprehend the possibilities of biology. Prof. F. T. Brooks, University of Cambridge, suggested that the wide extension of 'refresher' courses in the universities would make a valuable contribution to meet present deficiencies.

The part played by biological education in contributing to the welfare of native societies was described by delegates from New Zealand, Australia, Africa, Malaya, West Indies, Ceylon and other parts of the Empire. Sir Frank Stockdale, agricultural adviser to the Colonial Office, emphasized the need for co-operation between education, agricultural and health officers of communities that live close to the soil. In most tropical countries, a bias is already being given to education in teaching improved methods of agriculture, personal and social hygiene, housing and sanitation. In this connexion the need for an adequate training of teachers in human biology was stressed by many of the colonial visitors.

\section{OBITUARIES}

Maria Ogilvie Gordon, D.B.E.

$\mathrm{D}$ AME MARIA OGILVIE GORDON died on June 24, and with her has passed a pioneer in woman's share of scientific education and research. Eldest daughter of the Rev. Alexander Ogilvie of Aberdeen, she received her schooling in Edinburgh. She then, 1889-90, studied at University College, London, where she won the gold medal for zoology and comparative anatomy under Ray Lankester. In 1893 she was awarded the London D.Sc. Meanwhile, 1891-95, she had undertaken an investigation of recent and fossil corals under Hertwig and Zittel at Munich. She could not in those days enter the University of Munich as an official student, but merely as a private research worker, receiving kindly assist. ance from the professors and others of the staff. Under these conditions she published two important papers on corals, one in the Transactions of the Royal Society and the other as a supplement to Palceonto. graphica. In recognition of their merit, sho was in 1900 granted tho $\mathrm{Ph} . \mathrm{D}$. of Munich with highest honours. The occasion was specially noteworthy because it was the first time this degree had been conferred upon a woman.

Corals led Dame Maria into other fields than zoology and palæontology. In 1891, she accompanied Baron von Richthofen on a geological excursion to the South Tyrol, and listened to him expounding his thirty-year-old application of Darwin's theory of atolls to the irregularly disposed Triassic dolomites 